University of Wollongong

Research Online

Australian Institute for Innovative Materials -

Papers

Australian Institute for Innovative Materials

$1-1-2015$

The potential of induced pluripotent stem cells in models of neurological disorders: Implications on future therapy

Jeremy M. Crook

University of Wollongong, jcrook@uow.edu.au

Gordon G. Wallace

University of Wollongong, gwallace@uow.edu.au

Eva Tomaskovic-Crook

University of Wollongong, evatc@uow.edu.au

Follow this and additional works at: https://ro.uow.edu.au/aiimpapers

Part of the Engineering Commons, and the Physical Sciences and Mathematics Commons

Research Online is the open access institutional repository for the University of Wollongong. For further information contact the UOW Library: research-pubs@uow.edu.au 


\title{
The potential of induced pluripotent stem cells in models of neurological disorders: Implications on future therapy
}

\author{
Abstract \\ There is an urgent need for new and advanced approaches to modeling the pathological mechanisms of \\ complex human neurological disorders. This is underscored by the decline in pharmaceutical research \\ and development efficiency resulting in a relative decrease in new drug launches in the last several \\ decades. Induced pluripotent stem cells represent a new tool to overcome many of the shortcomings of \\ conventional methods, enabling live human neural cell modeling of complex conditions relating to \\ aberrant neurodevelopment, such as schizophrenia, epilepsy and autism as well as age-associated \\ neurodegeneration. This review considers the current status of induced pluripotent stem cell-based \\ modeling of neurological disorders, canvassing proven and putative advantages, current constraints, and \\ future prospects of next-generation culture systems for biomedical research and translation.

\section{Keywords} \\ cells, stem, pluripotent, therapy, future, implications, induced, disorders, potential, neurological, models

\section{Disciplines} \\ Engineering | Physical Sciences and Mathematics

\section{Publication Details} \\ Crook, J. Micah., Wallace, G. \& Tomaskovic-Crook, E. (2015). The potential of induced pluripotent stem \\ cells in models of neurological disorders: Implications on future therapy. Expert Review of \\ Neurotherapeutics: a key contribution to decision making in the treatment of neurologic and \\ neuropsychiatric disorders, 15 (3), 295-304. Expert Review of Neurotherapeutics
}


The potential of induced pluripotent stem cells in models of neurological disorders: implications on future therapy

Jeremy Micah Crook ${ }^{1-3}$, Gordon Wallace ${ }^{1}$, Eva Tomaskovic-Crook ${ }^{1,3}$

${ }^{1}$ ARC Centre of Excellence for Electromaterials Science, Intelligent Polymer Research Institute, AlIM Facility, Innovation Campus, University of Wollongong, Squires Way, Fairy Meadow, New South Wales 2519, Australia

${ }^{2}$ Department of Surgery, St Vincent's Hospital, The University of Melbourne, Fitzroy, Victoria 3065, Australia

${ }^{3}$ Illawarra Health and Medical Research Institute, University of Wollongong, Wollongong, New South Wales 2522, Australia

${ }^{+}$Author for correspondence:

ARC Centre of Excellence for Electromaterials Science, Intelligent Polymer Research Institute, AllM Facility, Innovation Campus, University of Wollongong, Squires Way, Fairy Meadow, New South Wales 2519, Australia

jcrook@uow.edu.au 


\section{The potential of induced pluripotent stem cells in models of neurological disorders: implications on future therapy}

\section{Summary}

There is an urgent need for new and advanced approaches to modelling the pathological mechanisms of complex human neurological disorders. This is underscored by the decline in pharmaceutical research and development efficiency resulting in a relative decrease in new drug launches in the last several decades. Induced pluripotent stem cells represent a new tool to overcome many of the shortcomings of conventional methods, enabling live human neural cell modelling of complex conditions relating to aberrant neurodevelopment, such as schizophrenia, epilepsy, and autism, as well as ageassociated neurodegeneration. This review considers the current status of induced pluripotent stem cell-based modelling of neurological disorders, canvassing proven and putative advantages, current constraints, and future prospects of next-generational culture systems for biomedical research and translation.

\section{Keywords}

induced pluripotent stem cells, neurological disorders, modelling, biomaterials, drug screening, tissue engineering, regenerative medicine, therapy. 
Induced pluripotent stem cells (iPSCs) proffer new opportunities to research complex neurological disorders, extant therapies, and develop treatments with improved and personalised efficacy including in vitro detection of neurotoxicity. As stem cells engineered from readily obtained somatic cells, iPSCs are able to be derived from patients of all ages with disorders of development and/or neurodegeneration, and provide insight to etiopathology previously unattainable by conventional approaches. That is not to say that iPSC-based research supersedes other methods such as animalbased modelling or human brain tissue studies, but rather it enables a complimentary line of research to advance understanding and treatment of human disease-related neural-phenotypes using living cells and derivative tissues. For example, where analyses of post-mortem tissues have for the most part provided insight to the advanced phases of aberrant development and degeneration[1], and despite dramatic progress in experimental methods for using mice to study monogenic and polygenic traits with relevance to human disease, mouse modelling encompasses a minority of neurological diseases, frequently fails to express every trait of a disorder, while human iPSCs can be derived with the specific genetic traits of any disease from any patient during their entire lifetime. Cells can therefore be used to recapitulate the different stages of a disease and model singular or cumulative effects of defective genes. Additionally, since most diseases involve interaction with environmental risk factors, more sophisticated iPSC-based modelling can incorporate relevant physical and chemical stimuli able to be rigorously controlled and investigated[2]. This approach will be especially useful for studying sporadic or idiopathic forms of a disease to understand gene-environment interactions and disease pathogenesis. 


\section{iPSC-based models of neurological disorders}

Human neurological disorders can involve the central and peripheral structures of the nervous system and be due to traumatic injury (TI), aberrant neurodevelopment (NDv) and neurodegeneration (NDg). Whereas TI is caused by a focal impact with primary damage at the time of injury and secondary damage in the days thereafter, NDv disorders relate to pre- and post-natal anomalies of the developing nervous system, and NDg disorders are characterised by prolonged neural deterioration due to disease progression. Both NDv and NDg disorders are often associated with specific genetic lesions but can involve non-hereditary stimuli such as environmental stressors. In any event, the short- or long-term outcome will typically be aberrant neuronal morphology, branching and connectivity, with TI and NDg disorders also associated with cell death.

Notwithstanding the potential utility of iPSCs for modelling TI in vitro, unlike NDv and NDg disorders, the significance is for the most part limited to providing an alternative source of neural cells and tissues to evaluate the effects of TI and develop strategies to improve cell survival after trauma and endogenous neural stem cell mobilisation to form new functional neurons at the site of injury. Other stem and progenitor cells able to be differentiated to neural lineage can fulfil the same role and animal models for in vivo research and development (R\&D) are available. Predictably, to the best of our knowledge, no iPSC-based modelling of TI has been described to date. By comparison, disease-specific iPSCs provide new prospects for disease-related R\&D by enabling screening for genes and disease processes potentially modifiable by drugs identified through in vitro screening. Consequently, iPSCs have been successfully derived from patients with NDv disorders including schizophrenia[3-11], Down's syndrome[12-21], autism spectrum disorders (ASDs) including fragile X, Rett and Timothy syndromes[22-35], and epilepsy[36-39], as well as NDg disorders such as 
Alzheimer's disease[40-48], Parkinson's disease[49-64], Huntington's disease[65-71], spinal muscular atrophy (SMA)[72-75], amyotrophic lateral sclerosis (ALS) [76-86], and Friedreich's ataxia [87-89].

As the field moves beyond proof-of-concept for the utility of patient-specific iPSCs, modelling is growing exponentially, with increasingly sophisticated culture systems, cell lines, and characterisation for more informative readouts. A topical study by Bilican et al (2012) of iPSCs derived from patients with ALS report an increased sensitivity to a stressor measured by a lactate dehydrogenase (LDH) release assay to measure neuronal survival[86]. The difference between ALS and control cells was not apparent under basal culture conditions, underscoring the need for innovative modelling paradigms to identify potentially significant disease-associated phenotypes.

Another recent study of iPSC-derived neurons from PD patients, demonstrates the importance of selecting appropriate control iPSCs beyond conventional "healthy" cell-lines by showing the need for isogenic gene-corrected hiPSC lines to detect changes specifically associated with mutant Leucine-rich repeat kinase 2 (LRRK2) gene[90]. The mutant phenotypes were not evident using iPSC lines derived from age- and sexmatched control patients.

It is ever more apparent that different disorders will have different requirements for optimal modelling. Similarly, modelling complex and heterogeneous disorders (such as ALS, schizophrenia and ASDs) will undoubtedly benefit from selecting donor cohorts of patients with similar clinical phenotypes, case histories, therapeutic responses and, wherever possible, common genotypes, in addition to tailoring cell culture conditions to account for putative relevant non-hereditary environmental triggers for disease onset.

\section{Neural differentiation of iPSCs: Quality and quantity}


The ability to differentiate iPSCs to bone fide neurones and supporting cells that accurately imitate the form and function of cells and tissue of the developing and diseased nervous system is a fundamental requirement for modelling. For instance, refinement of differentiation methods to develop specific neuronal subpopulations that are preferentially impaired in a disease will enable more specific and informative mechanistic studies[30]. In spite of a myriad of methods published to date, many based on early protocols for human embryonic stem cell (hESC) differentiation[30,91-95], their application is ordinarily hindered by low and variable efficiency[95]. Although the problem may in part relate to the differentiability of different iPSC lines, incomplete reporting and poor standardisation of process and reagents are likely contributing factors. The former is more difficult to address, however, the latter should theoretically be easily remedied through use of quality controlled cells, processes and reagents, as well as detailed, accurate and transparent reporting of old and new methods employed for publication.

While operators within academic and other publically or privately funded laboratories are presumed to systematically and meticulously develop and execute firstrate protocols for repeatable and precise in-house experimentation, translation for application by the wider field can be hindered by inadvertent or intentional omission of seemingly cursory actions from published documentation, and constrained research budgets can favour the use of cheaper lower grade consumables for R\&D. While not the whole solution, advocating standards for the quality and disclosure of materials and methods used to maintain, culture and differentiate iPSCs, including both their strengths and limits, will benefit both research and translation of modelling[96-98]. To this end, influential bodies such as granting agencies, publishing houses and perhaps even regulatory bodies have important roles to play by requiring compliance with 
standards in order for a research laboratory to obtain funding, publish and gain approval for clinical trials or therapeutic goods/products[97,98].

In spite of the above mentioned challenges, improvements for iPSC differentiation to neural cells and tissues are being made through the development of better defined, optimised and efficient protocols[30,99-103], bolstered by increased availability of superior stem cells attributable to improved somatic cell reprogramming, stem cell culture, banking and distribution[104-107]. A major advance from traditional differentiation methods is the circumvention of embryoid body (EB) formation for more efficient and direct induction of neural progenitor cells (NPCs) and expansion of neurospheres[99-102]. For example, Lie et al proffers high yield production of NPCs from feeder-free iPSC aggregates cultured in mTeSR ${ }^{\mathrm{TM}} 1$ (Stem Cell Technologies)[99]. Intermediate steps include sequential differentiation over 15 days of stem cell aggregates to monolayer neural rosettes that are expanded into free-floating neurospheres[99]. NPCs can be further differentiated into a variety of neuronal subtypes, including dopaminergic neurons within 21 days.

A more protracted method by Shi et al induces iPSCs over 90 days to excitatory "cortical projection" neurons, with intermediate "cortical primary" stem/progenitor cells formed within 2 weeks, followed by "early-born" neurons produced between 2-3 weeks, and "last-born" neurons arising as late as day 90 [100]. The method is based on a much earlier protocol of SMAD signalling inhibition[93], and is purportedly highly efficient and less variable among different cell lines due to replacing noggin with SMAD inhibitor dorsomorphin[100]. In addition to modelling cortical cell function and dysfunction, the authors assert the utility of their approach for cortical tissue engineering for transplantation. 
Shofuda et al propose a three stage protocol for generating neurospheres from human iPSCs by initially using human recombinant noggin medium and poly-Llysine/laminin substrate to induce NPCs, followed by neurosphere formation with FGF2/heparin medium in low-attachment polyethylene glycol coated microwell plates, and finally neurosphere expansion with EGF/FGF2/LIF medium in flasks [101]. The use of microwell plates ostensibly facilitates quicker, efficient, reliable and more standardised production of neurospheres, and draws from the use of microwell systems for more standardised culture of stem cells and other cells including EBs[101].

A fourth and most recent method by Musah et al represents a different approach to neuronal induction by using substratum mechanics rather than soluble signalling factors to regulate neuronal specification from iPSCs[103]. Consistent with advances in biomaterials based cell support and tissue engineering (see below section), whereby physical and other non-chemical stimuli are increasingly being applied to regulate cell fate, Musah and colleagues use hydrogels with elasticity similar to brain tissue to rapidly and efficiently differentiate iPSCs to neurons. Surprisingly, neuronal induction is achievable with mTeSR ${ }^{\mathrm{TM}} 1$-based culture medium (with or without medium components FGF2, TGF- $\beta$ or GABA) or basal (DMEM/F12) medium. The protocol underscores the importance and utility of cell substratum for stem cell differentiation, and highlights unconventional cell signalling pathways such as transcriptional co-activator Yesassociated-protein (YAP) as useful targets for controlling neural induction in conjunction with ubiquitous soluble factor signalling (eg. SMAD).

\section{Modelling with biomaterials: The way for the future}

Traditional protocols for iPSC maintenance and differentiation rely on methods originally devised for hESCs using two-dimensional (2-D) culture on smooth and 
inflexible surfaces such as glass or plastic, with growth media, biochemical supplements such as recombinant growth factors, and either a feeder layer of mitotically-inactivated mouse or human fibroblasts, or feeder free[108-113]. Feeder free platforms are preferable for both R\&D and clinical product development (ie. to simplify process and facilitate scale-up from laboratory-based research to industrial-scale biomedicine) and incorporate specialist media, for example $\operatorname{mTeSR}^{\mathrm{TM}}[110,111]$, StemPro® (Life Technologies), and Essential $8^{\mathrm{TM}}$ (Life Technologies)[114], with more or less complex substrates such as Matrigel $^{\mathrm{TM}}$ (Becton-Dickenson; a solubilized basement membrane preparation extracted from mouse Engelbreth-Holm-Swarm sarcoma), single or combinations of extracellular matrix (ECM) proteins such as laminin, fibronectin, vitronectin, and collagen, cell adhesion proteins including E-cadherin, or synthetic

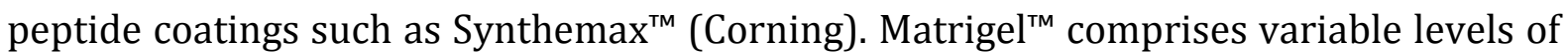
proteins and growth factors, including laminin, collagen IV, heparan sulfate proteoglycans, and entactin (nidogen), as well as substantial amounts of sarcoma derived growth factors such as TGF- $\beta$, fibroblast growth factor, and insulin-like growth factor. Other more defined culture surfaces include Primorigen's StemAdhere ${ }^{\mathrm{TM}}$ and Vitronectin $\mathrm{XF}^{\mathrm{TM}}$, both of which are xenobiotic-free.

Although useful, the classical approaches described above fall short of recapitulating the complex and dynamic environment of cells in vivo (ie. the cell niche), with conventional flat-bed culture on a dish or in a flask predictably resulting in markedly different cell behaviour[115]. There is, therefore, scope for newer systems that provide biomimetic environments to create conditions for cells to better mimic their in vivo counterparts. Initial strategies have focused on using biocompatible materials with properties of ECM that support cell growth, including ECM stiffness and related mechanical signals for improved and directed cell migration, proliferation and 
fate. More recently, electrical stimulation using conductive materials has been shown to effect proliferation, differentiation, migration, and changes in cell adhesion. Not surprisingly, the mechanical and electrical properties of tissues are altered in many disease states, resulting in cellular dysfunction and disease progression. Also, endogenous electric fields occur in body tissues as transepithelial cellular potentials or neuronal field potentials, and are important for tissue regeneration following injury and during embryonic and fetal development, with disturbances to environmental electric fields causing aberrant development[116-119]. Accordingly, elastic modulus and surface properties (eg. topography/roughness) of cell culture substrates and electrical stimulation are being used to control stem cell behaviour and function for basic research and future translational application. To this end, natural and synthetic biomaterials are being identified with different mechanical, chemical, electrical, and physical features of micro- and nanoscale proportions to control cell fate and function for in vitro modelling of neural tissues and disease phenotypes [120,121].

Natural biomaterials include Polysaccharides as important components of extracellular matrix (ECM) that can be formulated to rapidly gel for 3-dimensional (3-D) bioprinting, and have been used in various combinations for culture and differentiation of pluripotent stem cells [122-127]. Commonly employed polysaccharide-based 3-D scaffolds include collagen, gelatin, agarose, hyaluronic acid, elastin, alginate and chitosan, each having the potential for use in combination with iPSCs for neural tissue engineering. Not surprisingly, ECM has informed the development of platforms and constructs based on natural biomaterials. Advantages include biocompatibility (essential for in vitro cell interfacing, transplanted cell support in vivo and related endogenous/host tissue compatibility) and bioactivity with materials supporting cell adhesion and survival, induction of iPSC differentiation, and structural support of 
engineered tissues. Disadvantages relate to quality control with variable purity and biological activity from one lot to another, and limited mechanical properties. Synthetic biomaterials, on the other hand, have the advantage of being more defined and controllable (through, for example, fabrication) so as to conform to required specifications concerning nanotopography, chemical composition, stability and functionality, stiffness, adhesiveness and binding affinity, degradability and related byproducts[128].

Biomaterials can therefore be tailored to support and regulate iPSCs and derivative neuronal cells, carry and release drugs and other compounds, and degrade over a set period of time so as to meet the rigorous requirements for pharmaceutical drug screening and clinical use. While disadvantages can include poor biocompatibility resulting in poor cell adhesion, survival, self-renewal, differentiability and transplantability, the inherent capacity for refinement through design and reengineering provides opportunities to systematically optimise performance and application (FIGURE 1).

Although there have been few reports to date of biomaterial based iPSC culture for neural induction, the ability for materials to interface with hESCs for neural differentiation is indubitably applicable. Nevertheless, a recent landmark report involving both hESCs and iPSCs describes 3-D poly( $N$-isopropylacrylamide)-copoly(ethylene glycol) (PNIPAAm-PEG) hydrogel support of stem cell expansion and differentiation [125](Table 1). PNIPAAm-PEG is a synthetic thermoresponsive hydrogel that is liquid at low temperature for cell loading, which solidifies at $37^{\circ} \mathrm{C}$ for subsequent 3-D cell culture, including directed differentiation to neuronal progenitors (NPs). The system ostensibly enables defined, good-manufacturing practice-compatible and large- 
scale expansion of both stem cells and NPs for translational application, including commercial-scale drug screening and clinical-scale use.

A second report of significance relates to the use of 3-D conductive carbon nanotube (CNT) composites as substrates to support and differentiate NPs derived from human iPSCs[129](Table 1). The CNTs were incorporated by vacuum-driven impregnation to electrospun poly(lactic-co-glycolic acid) (PLGA) membranes and shown to enhance differentiation of iPSC derived NPs, further augmented by electrical stimulation. Similar to Lei and Schaffer described above, the authors proffer their platform for drug discovery, disease modelling and in vivo transplantation including facilitation of exogenous cell delivery and integration.

In recognising the important role of biomaterials in next generation stem cell technology including tissue engineering and regenerative medicine, like others, we at the ARC Centre of Excellence for Electromaterials Science are undertaking R\&D in the additive manufacturing or 3-D bioprinting (BP) space to reproducibly interface natural and synthetic materials with human iPSCs towards solving the many and unique challenges in neural tissue engineering and disease modelling. To this end, we are developing optimal and novel bioinks primarily for extrusion printing, comprising iPSCs, biocompatible gel composites, and other components for supporting cell growth and differentiation to neural lineage. While currently we are printing single cell types for in situ differentiation, we will progress to more complex multicellular printing and placement for more efficient and germane construct design, with the holy-grail for developing multidimensional "live" constructs being able to support vascularisation towards formation of clinical-scale tissues and whole-organ substitutes[130]. Incorporation of vascular networks will also benefit metabolically active neural constructs, currently limited to millimetre thickness. 


\section{Expert commentary}

'Based on the remarkable complexity of the human nervous system, and in particular the brain, it is the least understood body system and is difficult to model with conventional technology. Short of modelling the human CNS as a whole, models must ideally be humanised, diverse, complimentary and be explicitly defined in terms of what they simulate. To this end, human patient/disease-specific iPSC modelling provides an opportunity to unravel the complexity behind neurological function and disease in a way that has never been possible before. As cells containing the actual genetic information of the patients from which they are derived and able to be differentiated to mixed and subtype-specific neuronal populations both in 2-D and 3-D configurations, iPSCs are suited to modelling NDv disorders, enhanced by their presumed early developmental status, as well as NDg disorders by providing a pathological context to elucidate aberrant biological processes for therapeutic targeting including halting endogenous disease progression without neurotoxicity, and where necessary concomitant tissue regeneration. Importantly, toxicity testing is vital to determining the clinical efficacy of a drug or device, and relates to both chemical and physical impairment[131,132]. The developing brain is particularly sensitive to chemical perturbations. In vitro iPSC-based systems potentially offer a cost and time effective approach to identifying and characterising neurotoxicity, being amenable to mechanistic studies at both cellular and molecular levels, as well as ranking neurotoxicants for toxic potency. Therefore, neural-specific endpoints for screening putative neurotoxicants would include neuro-chemical, -morphologic, and transmission functions. 
In recognising the value of iPSC modelling though, there are a number of challenges required to be overcome before their potential as clinically relevant ex vivo models of neurological disorders can be fully realised. A critical requirement is to demonstrate robust and reproducible cell phenotypes relating to both normal and aberrant function. This will depend on overcoming shortfalls in knowledge about iPSC biology including the effects of cell reprograming, transcriptional memory of primary cells, cell-line variability in pluripotency and differentiability, impact of donor age and associated cell line maturation, as well as related standardisation of cell culture and characterisation. In addition, complex genetic conditions such as schizophrenia with heterogenous clinical etiologies and symptoms will benefit from developing iPSC study cohorts of patients with common clinical manifestations and/or genomic mutations[7]. This is particularly important for small donor-cohorts characteristic of iPSC-based modelling.

Through better understanding of the various modalities, more controllable systems with properties that are tailored to modelling specific neural cells and disorders of interest can be developed. This should ideally extend to being compatible with necessary characterisation tools and minimally incorporate key components of the in vivo cellular microenvironment as critical stimuli of normal and anomalous cell behaviour. The latter will likely require a biomaterials-based approach whereby synthetic, natural and functionalised materials will interface with iPSCs and iPSCderived neural tissues via inherent and engineered physical and chemical properties. The ability to spatially modulate composition and function using emerging approaches such as 3-D printing provides an unprecedented opportunity to systematically probe and control cellular behaviour. Ironically, the use of material properties to dictate clinically relevant cell phenotypes ex vivo will be paralleled by material-mediated 
correction of aberrant cellular function as a potential therapeutic strategy for TI's, NDds and NDgs. The materials may be fabricated into scaffolds, encapsulating gels or probes to generate healthy autologous tissues in vitro from diseased tissues for in vivo grafting, and/or optimised as medical devices to modify endogenous cells and tissues. While the jury is still out, it is hoped that in addition to generating more efficacious systems, harnessing the inductive capabilities of biomaterials will circumvent current costbarriers caused by inefficient and expensive bioprocessing, including reducing or omitting the need for biochemical reagents[128].

\section{Five-year view}

The next five years will see a rapid transition from first generation iPSC-based modelling using simple 2-D study paradigms to more sophisticated and clinicallyrelevant second-generation systems that incorporate, for example, extracellular stimuli with patient-specific cells and 3-D tissues using "smart" biomaterials and microfluidics[133,134]. Although there are challenges, a number of which are highlighted above, there is sufficient evidence for being able to recapitulate with iPSCs the neuropathologies of various neurological disorders to further elucidate underlying cellular and molecular mechanisms that have heretofore been unknown. Combined with increasing recognition of the importance of standards for modelling, including iPSC culture, differentiation and characterisation, the body of knowledge will continue to increase exponentially, ultimately benefiting progress in therapy.

\section{Acknowledgements}

The authors wish to acknowledge financial support of the Australian Research Council (ARC) and the ARC Centre of Excellence for Electromaterials Science (ACES). Professor 
Gordon Wallace additionally acknowledges the support of the ARC through an ARC Laureate Fellowship.

\section{References}

Papers of special note are highlighted as:

- of interest

•• of considerable interest

1. Cai S, Chan YS, Shum DK. Induced pluripotent stem cells and neurological disease models. Sheng Li Xue Bao, 66(1), 55-66 (2014).

2. Cherry $A B$, Daley $G Q$. Reprogramming cellular identity for regenerative medicine. Cell, 148(6), 1110-1122 (2012).

3. Wen Z, Nguyen HN, Guo Z et al. Synaptic dysregulation in a human iPS cell model of mental disorders. Nature, (2014).

4. Wright R, Rethelyi JM, Gage FH. Enhancing induced pluripotent stem cell models of schizophrenia. JAMA Psychiatry, 71(3), 334-335 (2014).

5. Brennand K, Savas JN, Kim Y et al. Phenotypic differences in hiPSC NPCs derived from patients with schizophrenia. Mol Psychiatry, (2014).

6. Brennand KJ, Gage FH. Concise review: the promise of human induced pluripotent stem cellbased studies of schizophrenia. Stem Cells, 29(12), 1915-1922 (2011).

7. Brennand KJ, Landek-Salgado MA, Sawa A. Modeling heterogeneous patients with a clinical diagnosis of schizophrenia with induced pluripotent stem cells. Biol Psychiatry, 75(12), 936944 (2014).

8. Brennand $\mathrm{KJ}$, Simone A, Jou J et al. Modelling schizophrenia using human induced pluripotent stem cells. Nature, 473(7346), 221-225 (2011).

9. Brennand KJ, Simone A, Tran N, Gage FH. Modeling psychiatric disorders at the cellular and network levels. Mol Psychiatry, 17(12), 1239-1253 (2012).

10. Chiang $\mathrm{CH}$, Su $\mathrm{Y}$, Wen $\mathrm{Z}$ et al. Integration-free induced pluripotent stem cells derived from schizophrenia patients with a DISC1 mutation. Mol Psychiatry, 16(4), 358-360 (2011).

\section{- First report of patient-specific iPSC-based modelling of schizophrenia.}

11. Pedrosa E, Sandler V, Shah A et al. Development of patient-specific neurons in schizophrenia using induced pluripotent stem cells. J Neurogenet, 25(3), 88-103 (2011).

12. Mukherjee S, Pipino C, David AL, DeCoppi P, Thrasher AJ. Emerging neuronal precursors from amniotic fluid-derived down syndrome induced pluripotent stem cells. Hum Gene Ther, 25(8), 682-683 (2014).

13. Shi Y, Kirwan P, Smith J, MacLean G, Orkin SH, Livesey FJ. A human stem cell model of early Alzheimer's disease pathology in Down syndrome. Sci Transl Med, 4(124), 124ra129 (2012).

14. Weick JP, Held DL, Bonadurer GF, 3rd et al. Deficits in human trisomy 21 iPSCs and neurons. Proc Natl Acad Sci U S A, 110(24), 9962-9967 (2013).

15. Briggs JA, Sun J, Shepherd J et al. Integration-free induced pluripotent stem cells model genetic and neural developmental features of down syndrome etiology. Stem Cells, 31(3), 467-478 (2013).

16. Chen $\mathrm{C}$, Jiang $\mathrm{P}, \mathrm{Xue} \mathrm{H}$ et al. Role of astroglia in Down's syndrome revealed by patientderived human-induced pluripotent stem cells. Nat Commun, 5, 4430 (2014).

17. Chou ST, Byrska-Bishop M, Tober JM et al. Trisomy 21-associated defects in human primitive hematopoiesis revealed through induced pluripotent stem cells. Proc Natl Acad Sci U S A, 109(43), 17573-17578 (2012). 
18. Hibaoui Y, Grad I, Letourneau A et al. Modelling and rescuing neurodevelopmental defect of Down syndrome using induced pluripotent stem cells from monozygotic twins discordant for trisomy 21. EMBO Mol Med, 6(2), 259-277 (2014).

19. Li LB, Chang KH, Wang PR, Hirata RK, Papayannopoulou T, Russell DW. Trisomy correction in Down syndrome induced pluripotent stem cells. Cell Stem Cell, 11(5), 615-619 (2012).

20. Lu HE, Yang YC, Chen SM et al. Modeling neurogenesis impairment in Down syndrome with induced pluripotent stem cells from Trisomy 21 amniotic fluid cells. Exp Cell Res, 319(4), 498505 (2013).

21. Mou X, Wu Y, Cao H et al. Generation of disease-specific induced pluripotent stem cells from patients with different karyotypes of Down syndrome. Stem Cell Res Ther, 3(2), 14 (2012).

22. Brick DJ, Nethercott HE, Montesano $S$ et al. The Autism Spectrum Disorders Stem Cell Resource at Children's Hospital of Orange County: Implications for Disease Modeling and Drug Discovery. Stem Cells Transl Med, (2014).

23. Ananiev G, Williams EC, Li H, Chang Q. Isogenic pairs of wild type and mutant induced pluripotent stem cell (iPSC) lines from Rett syndrome patients as in vitro disease model. PLoS One, 6(9), e25255 (2011).

24. Bolte $S$, Willfors $C$, Berggren $S$ et al. The Roots of Autism and ADHD Twin Study in Sweden (RATSS). Twin Res Hum Genet, 17(3), 164-176 (2014).

25. Cheung AY, Horvath LM, Grafodatskaya D et al. Isolation of MECP2-null Rett Syndrome patient hiPS cells and isogenic controls through X-chromosome inactivation. Hum Mol Genet, 20(11), 2103-2115 (2011).

26. Cocks G, Curran S, Gami P et al. The utility of patient specific induced pluripotent stem cells for the modelling of Autistic Spectrum Disorders. Psychopharmacology (Berl), 231(6), 10791088 (2014).

27. DeRosa BA, Van Baaren JM, Dubey GK et al. Derivation of autism spectrum disorder-specific induced pluripotent stem cells from peripheral blood mononuclear cells. Neurosci Lett, 516(1), 9-14 (2012).

28. Doers ME, Musser MT, Nichol $\mathrm{R}$ et al. iPSC-derived forebrain neurons from FXS individuals show defects in initial neurite outgrowth. Stem Cells Dev, 23(15), 1777-1787 (2014).

29. Farra N, Zhang WB, Pasceri P, Eubanks JH, Salter MW, Ellis J. Rett syndrome induced pluripotent stem cell-derived neurons reveal novel neurophysiological alterations. $\mathrm{Mol}$ Psychiatry, 17(12), 1261-1271 (2012).

30. Kim DS, Ross PJ, Zaslavsky K, Ellis J. Optimizing neuronal differentiation from induced pluripotent stem cells to model ASD. Front Cell Neurosci, 8, 109 (2014).

31. Krey JF, Pasca SP, Shcheglovitov A et al. Timothy syndrome is associated with activitydependent dendritic retraction in rodent and human neurons. Nat Neurosci, 16(2), 201-209 (2013).

32. Liu EY, Scott CT. Great expectations: autism spectrum disorder and induced pluripotent stem cell technologies. Stem Cell Rev, 10(2), 145-150 (2014).

33. Liu J, Koscielska KA, Cao $Z$ et al. Signaling defects in iPSC-derived fragile $\mathrm{X}$ premutation neurons. Hum Mol Genet, 21(17), 3795-3805 (2012).

34. Marchetto MC, Carromeu C, Acab A et al. A model for neural development and treatment of Rett syndrome using human induced pluripotent stem cells. Cell, 143(4), 527-539 (2010).

35. Pasca SP, Portmann T, Voineagu I et al. Using iPSC-derived neurons to uncover cellular phenotypes associated with Timothy syndrome. Nat Med, 17(12), 1657-1662 (2011).

36. Liu Y, Lopez-Santiago LF, Yuan Y et al. Dravet syndrome patient-derived neurons suggest a novel epilepsy mechanism. Ann Neurol, 74(1), 128-139 (2013).

37. Muotri AR. Modeling epilepsy with pluripotent human cells. Epilepsy Behav, 14 Suppl 1, 8185 (2009).

38. Higurashi $\mathrm{N}$, Uchida $\mathrm{T}$, Lossin $\mathrm{C}$ et al. A human Dravet syndrome model from patient induced pluripotent stem cells. Mol Brain, 6, 19 (2013). 
39. Jiao J, Yang Y, Shi Y et al. Modeling Dravet syndrome using induced pluripotent stem cells (iPSCs) and directly converted neurons. Hum Mol Genet, 22(21), 4241-4252 (2013).

40. Mahairaki V, Ryu J, Peters A et al. Induced Pluripotent Stem Cells from Familial Alzheimer's Disease Patients Differentiate into Mature Neurons with Amyloidogenic Properties. Stem Cells Dev, (2014).

41. Duan L, Bhattacharyya BJ, Belmadani A, Pan L, Miller RJ, Kessler JA. Stem cell derived basal forebrain cholinergic neurons from Alzheimer's disease patients are more susceptible to cell death. Mol Neurodegener, 9, 3 (2014).

42. Israel MA, Goldstein LS. Capturing Alzheimer's disease genomes with induced pluripotent stem cells: prospects and challenges. Genome Med, 3(7), 49 (2011).

43. Israel MA, Yuan SH, Bardy $\mathrm{C}$ et al. Probing sporadic and familial Alzheimer's disease using induced pluripotent stem cells. Nature, 482(7384), 216-220 (2012).

44. Kondo $\mathrm{T}$, Asai $\mathrm{M}$, Tsukita $\mathrm{K}$ et al. Modeling Alzheimer's disease with iPSCs reveals stress phenotypes associated with intracellular Abeta and differential drug responsiveness. Cell Stem Cell, 12(4), 487-496 (2013).

45. Mohamet L, Miazga NJ, Ward CM. Familial Alzheimer's disease modelling using induced pluripotent stem cell technology. World J Stem Cells, 6(2), 239-247 (2014).

46. Ooi L, Sidhu K, Poljak A et al. Induced pluripotent stem cells as tools for disease modelling and drug discovery in Alzheimer's disease. J Neural Transm, 120(1), 103-111 (2013).

47. Sproul AA, Jacob S, Pre D et al. Characterization and molecular profiling of PSEN1 familial Alzheimer's disease iPSC-derived neural progenitors. PLoS One, 9(1), e84547 (2014).

48. Yagi T, Ito D, Okada $Y$ et al. [Modeling familial Alzheimer's disease with induced pluripotent stem cells]. Rinsho Shinkeigaku, 52(11), 1134-1136 (2012).

49. Zhao P, Luo Z, Tian W et al. Solving the puzzle of Parkinson's disease using induced pluripotent stem cells. Exp Biol Med (Maywood), (2014).

50. Beevers JE, Caffrey TM, Wade-Martins R. Induced pluripotent stem cell (iPSC)-derived dopaminergic models of Parkinson's disease. Biochem Soc Trans, 41(6), 1503-1508 (2013).

51. Byers B, Cord B, Nguyen HN et al. SNCA triplication Parkinson's patient's iPSC-derived DA neurons accumulate alpha-synuclein and are susceptible to oxidative stress. PLoS One, 6(11), e26159 (2011).

52. Byers B, Lee HL, Reijo Pera R. Modeling Parkinson's disease using induced pluripotent stem cells. Curr Neurol Neurosci Rep, 12(3), 237-242 (2012).

53. Cooper $\mathrm{O}$, Hallett $\mathrm{P}$, Isacson $\mathrm{O}$. Using stem cells and iPS cells to discover new treatments for Parkinson's disease. Parkinsonism Relat Disord, 18 Suppl 1, S14-16 (2012).

54. Cooper $\mathrm{O}$, Seo H, Andrabi S et al. Pharmacological rescue of mitochondrial deficits in iPSCderived neural cells from patients with familial Parkinson's disease. Sci Transl Med, 4(141), 141ra190 (2012).

55. Devine MJ, Ryten M, Vodicka P et al. Parkinson's disease induced pluripotent stem cells with triplication of the alpha-synuclein locus. Nat Commun, 2, 440 (2011).

56. Hartfield EM, Fernandes HJ, Vowles J, Cowley SA, Wade-Martins R. Cellular reprogramming: a new approach to modelling Parkinson's disease. Biochem Soc Trans, 40(5), 1152-1157 (2012).

57. Imaizumi $\mathrm{Y}$, Okada $\mathrm{Y}$, Akamatsu $\mathrm{W}$ et al. Mitochondrial dysfunction associated with increased oxidative stress and alpha-synuclein accumulation in PARK2 iPSC-derived neurons and postmortem brain tissue. Mol Brain, 5, 35 (2012).

58. Pu J, Jiang $\mathrm{H}$, Zhang B, Feng J. Redefining Parkinson's disease research using induced pluripotent stem cells. Curr Neurol Neurosci Rep, 12(4), 392-398 (2012).

59. Ryan SD, Dolatabadi N, Chan SF et al. Isogenic human iPSC Parkinson's model shows nitrosative stress-induced dysfunction in MEF2-PGC1alpha transcription. Cell, 155(6), 13511364 (2013). 
60. Sanchez-Danes A, Benzoni P, Memo M, Dell'Era P, Raya A, Consiglio A. Induced pluripotent stem cell-based studies of Parkinson's disease: challenges and promises. CNS Neurol Disord Drug Targets, 12(8), 1114-1127 (2013).

61. Sanchez-Danes A, Richaud-Patin Y, Carballo-Carbajal I et al. Disease-specific phenotypes in dopamine neurons from human iPS-based models of genetic and sporadic Parkinson's disease. EMBO Mol Med, 4(5), 380-395 (2012).

62. Sanders LH, Laganiere J, Cooper $\mathrm{O}$ et al. LRRK2 mutations cause mitochondrial DNA damage in iPSC-derived neural cells from Parkinson's disease patients: reversal by gene correction. Neurobiol Dis, 62, 381-386 (2014).

63. Schondorf DC, Aureli M, McAllister FE et al. iPSC-derived neurons from GBA1-associated Parkinson's disease patients show autophagic defects and impaired calcium homeostasis. Nat Commun, 5, 4028 (2014).

64. Soldner F, Hockemeyer D, Beard C et al. Parkinson's disease patient-derived induced pluripotent stem cells free of viral reprogramming factors. Cell, 136(5), 964-977 (2009).

65. Kaye JA, Finkbeiner S. Modeling Huntington's disease with induced pluripotent stem cells. Mol Cell Neurosci, 56, 50-64 (2013).

66. Camnasio S, Delli Carri A, Lombardo A et al. The first reported generation of several induced pluripotent stem cell lines from homozygous and heterozygous Huntington's disease patients demonstrates mutation related enhanced lysosomal activity. Neurobiol Dis, 46(1), 41-51 (2012).

67. Chae JI, Kim DW, Lee $\mathrm{N}$ et al. Quantitative proteomic analysis of induced pluripotent stem cells derived from a human Huntington's disease patient. Biochem J, 446(3), 359-371 (2012).

68. Guo X, Disatnik MH, Monbureau M, Shamloo M, Mochly-Rosen D, Qi X. Inhibition of mitochondrial fragmentation diminishes Huntington's disease-associated neurodegeneration. J Clin Invest, 123(12), 5371-5388 (2013).

69. Jeon I, Lee N, Li JY et al. Neuronal properties, in vivo effects, and pathology of a Huntington's disease patient-derived induced pluripotent stem cells. Stem Cells, 30(9), 2054-2062 (2012).

70. Juopperi TA, Kim WR, Chiang $\mathrm{CH}$ et al. Astrocytes generated from patient induced pluripotent stem cells recapitulate features of Huntington's disease patient cells. Mol Brain, 5, 17 (2012).

71. Zhang N, An MC, Montoro D, Ellerby LM. Characterization of Human Huntington's Disease Cell Model from Induced Pluripotent Stem Cells. PLoS Curr, 2, RRN1193 (2010).

72. Ebert $A D, Y u J$, Rose FF, Jr. et al. Induced pluripotent stem cells from a spinal muscular atrophy patient. Nature, 457(7227), 277-280 (2009).

73. Chang T, Zheng W, Tsark $W$ et al. Brief report: phenotypic rescue of induced pluripotent stem cell-derived motoneurons of a spinal muscular atrophy patient. Stem Cells, 29(12), 2090-2093 (2011).

74. Corti $\mathrm{S}$, Nizzardo $\mathrm{M}$, Simone $\mathrm{C}$ et al. Genetic correction of human induced pluripotent stem cells from patients with spinal muscular atrophy. Sci Transl Med, 4(165), 165ra162 (2012).

75. Nihei $Y$, Ito $D$, Okada $Y$ et al. Enhanced aggregation of androgen receptor in induced pluripotent stem cell-derived neurons from spinal and bulbar muscular atrophy. J Biol Chem, 288(12), 8043-8052 (2013).

76. Wainger BJ, Kiskinis E, Mellin C et al. Intrinsic membrane hyperexcitability of amyotrophic lateral sclerosis patient-derived motor neurons. Cell Rep, 7(1), 1-11 (2014).

77. Mitne-Neto M, Machado-Costa M, Marchetto MC et al. Downregulation of VAPB expression in motor neurons derived from induced pluripotent stem cells of ALS8 patients. Hum Mol Genet, 20(18), 3642-3652 (2011).

78. Nishimura AL, Shum C, Scotter EL et al. Allele-specific knockdown of ALS-associated mutant TDP-43 in neural stem cells derived from induced pluripotent stem cells. PLoS One, 9(3), e91269 (2014). 
79. Richard JP, Maragakis NJ. Induced pluripotent stem cells from ALS patients for disease modeling. Brain Res, (2014).

80. Sareen D, O'Rourke JG, Meera $P$ et al. Targeting RNA foci in iPSC-derived motor neurons from ALS patients with a C9ORF72 repeat expansion. Sci Transl Med, 5(208), 208ra149 (2013).

81. Yang YM, Gupta SK, Kim KJ et al. A small molecule screen in stem-cell-derived motor neurons identifies a kinase inhibitor as a candidate therapeutic for ALS. Cell Stem Cell, 12(6), 713-726 (2013).

82. Burkhardt MF, Martinez FJ, Wright $\mathrm{S}$ et al. A cellular model for sporadic ALS using patientderived induced pluripotent stem cells. Mol Cell Neurosci, 56, 355-364 (2013).

83. Chen H, Qian K, Du Z et al. Modeling ALS with iPSCs reveals that mutant SOD1 misregulates neurofilament balance in motor neurons. Cell Stem Cell, 14(6), 796-809 (2014).

84. Chestkov IV, Vasilieva EA, Illarioshkin SN, Lagarkova MA, Kiselev SL. Patient-Specific Induced Pluripotent Stem Cells for SOD1-Associated Amyotrophic Lateral Sclerosis Pathogenesis Studies. Acta Naturae, 6(1), 54-60 (2014).

85. Dimos JT, Rodolfa KT, Niakan KK et al. Induced pluripotent stem cells generated from patients with ALS can be differentiated into motor neurons. Science, 321(5893), 1218-1221 (2008).

- First report of patient-specific iPSC-based modelling of a neurological disorder.

86. Bilican B, Serio A, Barmada SJ et al. Mutant induced pluripotent stem cell lines recapitulate aspects of TDP-43 proteinopathies and reveal cell-specific vulnerability. Proc Natl Acad Sci U $S A, 109(15)$, 5803-5808 (2012).

-. Report highlighting the importance of advanced modelling paradigms to identify disease-associated phenotypes not apparent using conventional approaches.

87. Gottesfeld JM, Rusche JR, Pandolfo M. Increasing frataxin gene expression with histone deacetylase inhibitors as a therapeutic approach for Friedreich's ataxia. J Neurochem, 126 Suppl 1, 147-154 (2013).

88. Hick A, Wattenhofer-Donze M, Chintawar S et al. Neurons and cardiomyocytes derived from induced pluripotent stem cells as a model for mitochondrial defects in Friedreich's ataxia. Dis Model Mech, 6(3), 608-621 (2013).

89. Ku S, Soragni E, Campau E et al. Friedreich's ataxia induced pluripotent stem cells model intergenerational GAATTC triplet repeat instability. Cell Stem Cell, 7(5), 631-637 (2010).

90. Reinhardt P, Schmid B, Burbulla LF et al. Genetic correction of a LRRK2 mutation in human iPSCs links parkinsonian neurodegeneration to ERK-dependent changes in gene expression. Cell Stem Cell, 12(3), 354-367 (2013).

-• Report highlighting the importance of isogenic gene-corrected iPSC lines to identify mutant phenotypes not evident using conventional control donor cell lines.

91. Abranches E, Bekman E, Henrique D, Cabral JM. Expansion and neural differentiation of embryonic stem cells in adherent and suspension cultures. Biotechnol Lett, 25(9), 725-730 (2003).

92. Gerrard L, Rodgers L, Cui W. Differentiation of human embryonic stem cells to neural lineages in adherent culture by blocking bone morphogenetic protein signaling. Stem Cells, 23(9), 1234-1241 (2005).

93. Chambers SM, Fasano CA, Papapetrou EP, Tomishima M, Sadelain M, Studer L. Highly efficient neural conversion of human ES and iPS cells by dual inhibition of SMAD signaling. Nat Biotechnol, 27(3), 275-280 (2009).

94. Nemati S, Hatami M, Kiani S et al. Long-term self-renewable feeder-free human induced pluripotent stem cell-derived neural progenitors. Stem Cells Dev, 20(3), 503-514 (2011). 
95. Koehler KR, Tropel P, Theile JW et al. Extended passaging increases the efficiency of neural differentiation from induced pluripotent stem cells. BMC Neurosci, 12, 82 (2011).

96. Plant AL, Locascio LE, May WE, Gallagher PD. Improved reproducibility by assuring confidence in measurements in biomedical research. Nat Methods, 11(9), 895-898 (2014).

97. Stacey GN, Crook JM, Hei D, Ludwig T. Banking human induced pluripotent stem cells: lessons learned from embryonic stem cells? Cell Stem Cell, 13(4), 385-388 (2013).

98. Crook JM, Stacey G. Setting quality standards for stem cell banking, research and translation: The International Stem Cell Banking Initiative. In: Stem Cell Banking. Illic, D (Ed. (Human Press, New York, 2014) 3-9.

99. Lie KH, Chung HC, Sidhu KS. Derivation, propagation, and characterization of neuroprogenitors from pluripotent stem cells (hESCs and hiPSCs). Methods Mol Biol, 873, 237-246 (2012).

100. Shi Y, Kirwan P, Livesey FJ. Directed differentiation of human pluripotent stem cells to cerebral cortex neurons and neural networks. Nat Protoc, 7(10), 1836-1846 (2012).

101. Shofuda T, Fukusumi H, Kanematsu D et al. A method for efficiently generating neurospheres from human-induced pluripotent stem cells using microsphere arrays. Neuroreport, 24(2), 84-90 (2013).

102. Stover AE, Brick DJ, Nethercott HE et al. Process-based expansion and neural differentiation of human pluripotent stem cells for transplantation and disease modeling. $J$ Neurosci Res, 91(10), 1247-1262 (2013).

103. Musah S, Wrighton PJ, Zaltsman $Y$ et al. Substratum-induced differentiation of human pluripotent stem cells reveals the coactivator YAP is a potent regulator of neuronal specification. Proc Natl Acad Sci U S A, (2014).

-. Report highlighting the utility of substratum mechanics rather than soluble signalling to regulate neuronal specification from iPSCs.

104. Crook JM, Hei D, Stacey G. The International Stem Cell Banking Initiative (ISCBI): raising standards to bank on. In Vitro Cell Dev Biol Anim, 46(3-4), 169-172 (2010).

105. Bayart $\mathrm{E}$, Cohen-Haguenauer $\mathrm{O}$. Technological overview of iPS induction from human adult somatic cells. Curr Gene Ther, 13(2), 73-92 (2013).

106. Li J, Song W, Pan G, Zhou J. Advances in understanding the cell types and approaches used for generating induced pluripotent stem cells. J Hematol Oncol, 7(1), 50 (2014).

107. Ruetz T, Kaji K. Routes to induced pluripotent stem cells. Curr Opin Genet Dev, 28C, 38-42 (2014).

108. Thomson JA, Itskovitz-Eldor J, Shapiro SS et al. Embryonic stem cell lines derived from human blastocysts. Science, 282(5391), 1145-1147 (1998).

109. Crook JM, Peura TT, Kravets $L$ et al. The generation of six clinical-grade human embryonic stem cell lines. Cell Stem Cell, 1(5), 490-494 (2007).

110. Ludwig TE, Bergendahl V, Levenstein ME, Yu J, Probasco MD, Thomson JA. Feederindependent culture of human embryonic stem cells. Nat Methods, 3(8), 637-646 (2006).

111. Ludwig TE, Levenstein ME, Jones JM et al. Derivation of human embryonic stem cells in defined conditions. Nat Biotechnol, 24(2), 185-187 (2006).

112. Takahashi $\mathrm{K}$, Tanabe $\mathrm{K}$, Ohnuki $\mathrm{M}$ et al. Induction of pluripotent stem cells from adult human fibroblasts by defined factors. Cell, 131(5), 861-872 (2007).

113. Yu J, Vodyanik MA, Smuga-Otto $\mathrm{K}$ et al. Induced pluripotent stem cell lines derived from human somatic cells. Science, 318(5858), 1917-1920 (2007).

114. Chen G, Gulbranson DR, Hou Z et al. Chemically defined conditions for human iPSC derivation and culture. Nat Methods, 8(5), 424-429 (2011).

115. Lowry ER, Henderson CE. Stem cell differentiation: yielding substrates for neurons. Nat Mater, 13(6), 543-544 (2014).

116. Mycielska ME, Djamgoz MB. Cellular mechanisms of direct-current electric field effects: galvanotaxis and metastatic disease. J Cell Sci, 117(Pt 9), 1631-1639 (2004). 
117. Zhao M. Electrical fields in wound healing-An overriding signal that directs cell migration. Semin Cell Dev Biol, 20(6), 674-682 (2009).

118. Cameron IL, Hardman WE, Winters WD, Zimmerman S, Zimmerman AM. Environmental magnetic fields: influences on early embryogenesis. J Cell Biochem, 51(4), 417-425 (1993).

119. Robinson KR. The responses of cells to electrical fields: a review. J Cell Biol, 101(6), 20232027 (1985).

120. Kingham E, White K, Gadegaard N, Dalby MJ, Oreffo RO. Nanotopographical cues augment mesenchymal differentiation of human embryonic stem cells. Small, 9(12), 2140-2151 (2013).

121. Stewart E, Kobayashi NR, Higgins $M$ et al. Electrical Stimulation Using Conductive Polymer Polypyrrole Promotes Differentiation of Human Neural Stem Cells: A Biocompatible Platform for Translational Neural Tissue Engineering. Tissue Eng Part C Methods, (2014).

122. Bratt-Leal AM, Carpenedo RL, Ungrin MD, Zandstra PW, McDevitt TC. Incorporation of biomaterials in multicellular aggregates modulates pluripotent stem cell differentiation. Biomaterials, 32(1), 48-56 (2011).

123. Chang CW, Hwang Y, Brafman D, Hagan T, Phung C, Varghese S. Engineering cell-material interfaces for long-term expansion of human pluripotent stem cells. Biomaterials, 34(4), 912-921 (2013).

124. Giobbe GG, Zagallo $M$, Riello $M$ et al. Confined 3D microenvironment regulates early differentiation in human pluripotent stem cells. Biotechnol Bioeng, 109(12), 3119-3132 (2012).

125. Lei Y, Schaffer DV. A fully defined and scalable 3D culture system for human pluripotent stem cell expansion and differentiation. Proc Natl Acad Sci U S A, 110(52), E5039-5048 (2013).

•. Report highlighting defined, good-manufacturing practice compliant, 3-D, thermoresponsive hydrogel support of iPSC expansion and neural differentiation for modelling and clinical translation.

126. Lou YR, Kanninen L, Kuisma $T$ et al. The use of nanofibrillar cellulose hydrogel as a flexible three-dimensional model to culture human pluripotent stem cells. Stem Cells Dev, 23(4), 380-392 (2014).

127. Phillips BW, Horne R, Lay TS, Rust WL, Teck TT, Crook JM. Attachment and growth of human embryonic stem cells on microcarriers. J Biotechnol, 138(1-2), 24-32 (2008).

128. Murphy WL, McDevitt TC, Engler AJ. Materials as stem cell regulators. Nat Mater, 13(6), 547557 (2014).

129. Landers J, Turner JT, Heden G et al. Carbon nanotube composites as multifunctional substrates for in situ actuation of differentiation of human neural stem cells. Adv Healthc Mater, 3(11), 1745-1752 (2014).

130. Hoch E, Tovar GE, Borchers K. Bioprinting of artificial blood vessels: current approaches towards a demanding goal. Eur J Cardiothorac Surg, 46(5), 767-778 (2014).

131. Giordano G, Costa LG. Developmental neurotoxicity: some old and new issues. ISRN Toxicol, 2012, 814795 (2012).

132. Costa LG. Neurotoxicity testing: a discussion of in vitro alternatives. Environ Health Perspect, 106 Suppl 2, 505-510 (1998).

133. Shi M, Majumdar D, Gao Y et al. Glia co-culture with neurons in microfluidic platforms promotes the formation and stabilization of synaptic contacts. Lab Chip, 13(15), 3008-3021 (2013).

134. Kunze A, Giugliano M, Valero A, Renaud P. Micropatterning neural cell cultures in 3D with a multi-layered scaffold. Biomaterials, 32(8), 2088-2098 (2011). 


\section{Financial disclosure/Acknowledgements}

No competing financial interests exist.

3-D conductive material-cell construct

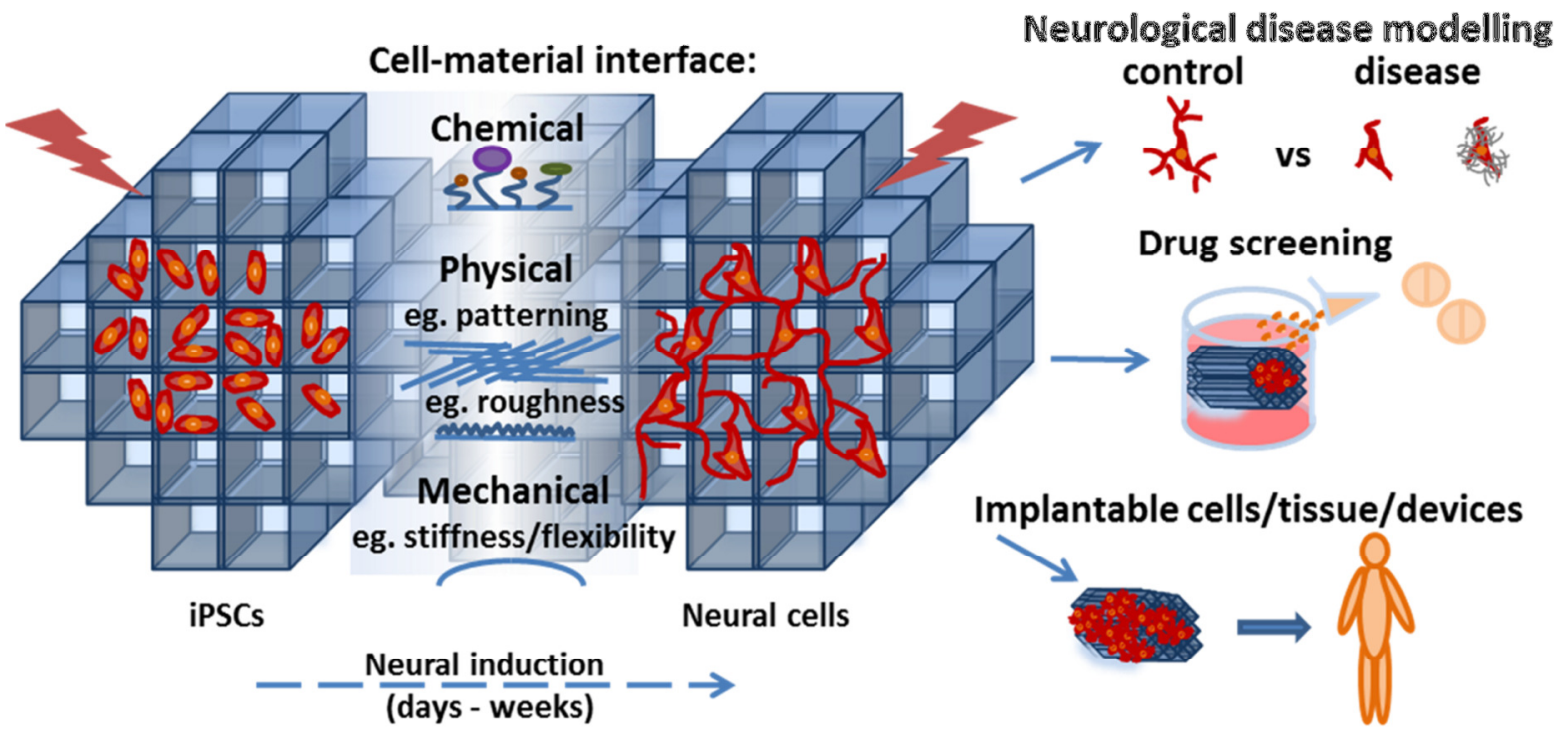

Figure 1. Schema of biomaterials-based iPSC culture and differentiation for advanced neurological disease modelling, early-phase drug screening, and development of implantable neural cells, tissues and medical devices. Biomaterials with suitable chemical, physical, mechanical, and electrical properties are being interfaced with iPSCs for expansion and to ameliorate neural induction for improved modelling of neural tissues and disease phenotypes. 